\title{
Manufacturing and metallization of hybrid thermoplastic-thermoset matrix composites
}

Hetal Parmar, Antonio Gambardella, Alessia Serena Perna, Antonio Viscusi, Roberta Della Gatta, Fausto Tucci, Antonello Astarita and Pierpaolo Carlone

Hetal Parmar. Department of Industrial Engineering, University of Salerno, Via Giovanni Paolo II, 132, 84084 Fisciano (SA), Italy Antonio Gambardella. Department of Industrial Engineering, University of Salerno, Via Giovanni Paolo II, 132, 84084 Fisciano (SA), Italy

Alessia Serena Perna. Department of Chemical, Materials and Production Engineering, University of Naples Federico II, Piazzale Tecchio, 80, Napoli (NA), Italy

Antonio Viscusi. Department of Chemical, Materials and Production Engineering, University of Naples Federico II, Piazzale Tecchio, 80, Napoli (NA), Italy

Roberta Della Gatta. Department of Chemical, Materials and Production Engineering, University of Naples Federico II, Piazzale Tecchio, 80, Napoli (NA), Italy

Fausto Tucci. Department of Industrial Engineering, University of Salerno, Via Giovanni Paolo II, 132, 84084 Fisciano (SA), Italy Antonello Astarita. Department of Chemical, Materials and Production Engineering, University of Naples Federico II, Piazzale Tecchio, 80, Napoli (NA), Italy Pierpaolo Carlone. Department of Industrial Engineering, University of Salerno, Via Giovanni Paolo II, 132, 84084 Fisciano (SA), Italy

Corresponding author: pcarlone@unisa.it

Abstract. Metallization is a common strategy employed to enhance the electrical and thermal conductivity of polymer matrix composite materials. Nevertheless, metallic deposition on polymer-based materials is challenging due to the inherent limitations related to high temperature exposure of the substrate. In this article, a new technique for the manufacturing of composite laminates and the subsequent metallization by cold spraying of metallic powder is presented. The composite manufacturing route is based on the production of thermoplastic-thermoset hybrid substrates and consisted of two main stages: in the first stage the partial impregnation of a reinforcement textile by a thermoplastic film was promoted by hot pressing compaction. Afterwards, the prepared lamina was vacuum bagged with other reinforcing layers and impregnated by the thermoset catalyzed resin by a vacuum infusion process. Finally, the thermoset and thermoplastic layers were co-cured to increase the adhesion of the substrate with the thermoplastic film. The metallization of composite laminate was obtained through the cold spraying technique, depositing powders on the thermoplastic surface layer. The effect of processing parameters on the coating deposition, quality and microstructure was reported and discussed.

Keywords. Metallization, Polymer Matrix Composites, Fiber Reinforced Thermosets, Cocuring, Resin Infusion, Cold Spray

\section{Introduction}

Lightweight materials are currently widely adopted to optimize structures, transport systems and civil building [1,2]. Due to this reason, many scientific efforts have been devoted to the manufacturing and the optimization of fiber reinforced composites [3-7]. Aerospace sector has observed inculcation of different approaches to handle the weight reduction issue. The current research trend in this respect is to replace the metallic materials with lightweight, corrosion resistant alternatives such as polymer based composites [8-10]. Such incorporation can pose challenges in case of lightning strike issues due to the low poor electrical conductance of polymer and polymer based PMCs [11]. Hence, it is essential to provide the composites with improved properties. Metallization can provide a way to impart 
the necessary improvement in the electrical as well as thermal conductivity of polymer-based composites [12]. Recent research efforts have included cold spraying as a metallization method in comparison with the conventional techniques including physical vapor deposition (PVD) [13,14], chemical vapor deposition (CVD) [15], electroless plating [16], and thermal spraying [17]. These techniques contain inherent drawbacks of higher processing temperature and requirement of deposition in a semi-molten or molten state [18]. It can present challenges when the substrate materials are polymers and polymer-based composites. On the other hand, the cold spray (CS) process offers a metallic solid state deposition, without any liquid transition of depositing particles [19] and it is applicable for the low processing temperature polymers and PMCs [20]. Regarding this topic, in the past decade several research efforts were conducted to attain the understanding on the bonding mechanisms involving different materials. These studies were mainly constructed by varying the different processing parameters such as nozzle configurations, traverse speed, gas temperature and pressure, and powder feed rate [18,21]. The literature evidences received from the single particle impact experimentation by Chen et al. discussed mechanical interlocking to be the preliminary bonding mechanism of polymeric substrates $[11,18]$. Also, the lack of chemical reaction and diffusion results in no metallurgical bonding [22]. The process of metallizing the polymer based substrate contains two primary stages i.e. (1) the first layer formation which involves particle to substrate impingement and, (2) buildup of the coating which also involves particle to particle impact [23]. During the first stage of metallic deposition, thermal softening of polymer matrix occurs owing to the metallic particle impact and subsequent kinetic energy dissipation. The successful deposition is dependent on particle and carrier gas temperature particle velocity, and propelling gas pressures. In the study conducted by Giraud et al. of $\mathrm{Al}$ deposition on PA66 substrate, the carrier gas temperature increase was found to enhance the thermal softening of the polymer matrix. The thermal softening improved the polymer coverage around the metallic particle and in turn attained mechanical anchorage [11]. In another investigation by King et al. the spray temperature improvement from $150 \stackrel{\circ}{\circ} \mathrm{C}$ to $350 \stackrel{\circ}{\circ}$ resulted in mean particle embedding depth for the HDPE, PP, Nylon 6, PTFE, PC, and PU substrates [24]. Better polymer surface coverage was found to be provided by higher particle impact energy for the substrates HDPE and PTFE $[25,26]$. The low coating adhesion issue arising in case of low-pressure cold spray configurations can be averted by incorporating the interlayer materials during the CS $[9,10,27]$. Such approach provides a bond layer formation over the substrate on which the metallic coating can be further deposited. Considerable amount of literature suggests utilization of cold spray technique for the $\mathrm{Al}$ [11,28-30], $\mathrm{Cu}[9,18,24,27]$, Sn [31,32], Ti [33], Fe [31] deposition on the thermoplastic polymers. The thermoplastic based PMC composites metallization as well was studied to determine its effect on the electrical as well as mechanical property changes [34-37]. The similar two stage bonding mechanisms are also observed in case of metallization of PMCs. As demonstrated by Bortolussi et al. [35], the sprayed powder mixture and the particle morphology was found to influence the bonding process in case of continuous carbon fiber/PEEK combination. Other investigated combination includes the $\mathrm{Al} / \mathrm{Cu}$ deposition on PEEK based CFRP [37], Al deposition on PEEK reinforced CFRP [38], Cu on CFRP [36], and Al and Cu deposition on PEEK based CFRP [34]. Different research efforts were conducted to metallize the thermoset based CFRP and determine the influence of processing parameters on the coating generation [31,39-41]. In the literature survey, commonly observed challenges were matrix surface erosion and fiber exposure attributed to the brittle nature of the substrate [31,40,42,43]. For instance, Ganeshan et al. detected erosion and low DE for the thermoset epoxy substrate metallization with $\mathrm{Cu}$ [43]. Che et al. observed evident fracture of the carbon fibers and removal of epoxy resin from some areas in the Al cold spraying attempt on epoxy based CFRP [42]. Similarly, Al deposition on the thermoset based CFRP resulted in the coating peel off and matrix removal. For this some strategy of using low density depositing metals such as $\mathrm{Sn}$ or inserting a interlayer has been implemented for achieving deposition on the thermoset based PMCs [40]. In order to overcome the above-mentioned drawbacks, this investigation presents a new approach involving co-curing after the resin infusion stage and further follow with metallization via cold spray technique. The primary stage in this strategy was to manufacture a semi impregnated fiber reinforcement by a thermoplastic film flow by utilizing a hot compaction method. The next manufacturing stage entails resin infusion of the full stack and co-curing of the semi thermoplastic impregnated fiber panel with thermoset based resin. This in turn produced a hybrid thermoset based composites with thermoplastic layer which can provide a potential improvement in the cold spray ability of the panel. The microstructural analysis demonstrates the influence 
of the applied approach in the manufacturing stage as well as the considered processing parameters and its effect on coating quality.

\section{Materials and methods}

The materials used in the experimental work were glass fiber reinforcements, polypropylene (PP) thermoplastic film and a low viscosity epoxy resin. The main properties of the glass fiber can be found elsewhere [44]. Thermoset epoxy resin was employed in the resin infusion stage to impregnate through the PP semi impregnated glass fiber reinforced composite panels. The basic properties associated with the epoxy resin is enlisted in the Table 1 . The utilized thermoplastic polymer PP contained density of $0.95 \mathrm{~g} / \mathrm{cm}^{3}$ and thermal conductivity values of $0.22 \mathrm{~W} / \mathrm{m}^{*} \mathrm{~K}$.

Table 1. Properties of the SX10-evo epoxy resin and catalyst used during the infusion process

\begin{tabular}{|l|l|}
\hline Tensile strength $\left[\mathrm{N} / \mathrm{mm}^{2}\right]$ & $55-65$ \\
\hline Elongation at break [percentage] & $2-3$ \\
\hline Tensile modulus $\left[\mathrm{N} / \mathrm{mm}^{2}\right]$ & $2800-3000$ \\
\hline Flexural strength $\left[\mathrm{N} / \mathrm{mm}^{2}\right]$ & $85-95$ \\
\hline Flexural modulus $\left[\mathrm{N} / \mathrm{mm}^{2}\right]$ & $2500-3000$ \\
\hline Glass transition temperature $\left[{ }^{\circ} \mathrm{C}\right]$ & $50-58$ \\
\hline Maximum transition temperature $\left[{ }^{\circ} \mathrm{C}\right]$ & $82-89$ \\
\hline
\end{tabular}

The investigation involved two steps corresponding to the composite manufacturing and coating formation.

- Manufacturing of the hybrid laminates

As indicated in the Fig. 1, the hybrid composite manufacturing itself consisted of two main stages to form the thermoset infused fiber reinforcement stacks with the thermoplastic (PP) interlayer in order to assist in the further cold spraying procedure. Primarily the glass fiber reinforcement monolayer was hot compacted through hot press set up with the thermoplastic layer of PP to obtain a thermoplastic (PP) semi-impregnation into the fiber reinforcement (Fig. 1a). The glass fiber was placed in two configurations of above and below the PP layer during the hot compaction step to compare and determine the best possible configuration in which the compaction yields better adhesion. During the manufacturing of the $\mathrm{PP} /$ glass fiber panel, $150{ }^{\circ} \mathrm{C}$ test temperature was considered and further increased up to 160 ${ }^{\circ} \mathrm{C}$ since it was in the close range of the PP melting point. Followed by that, 30 minutes of dwell time was provided to ensure adequate flow of the thermoplastic inside the fiber. Secondary stage was to manufacture a hybrid composite by the resin infusion process. The laminate containing the first monolayer of PP infiltrated glass fiber reinforcement was placed along with the additional fiber reinforcement layers to form a composite under the resin infusion process. Followed by the vacuum bagging, epoxy resin was infused through the prepared lamina (Fig. 1b). The resin infusion proceeded under the negative vacuum pressure and the homogeneous resin flow was ensured without leakage from the exterior. The linear resin front can be observed from the Fig.1 b. Occurrences of the air bubbles and cavities are the most critical challenges associated with the infusion stage. Hence, to avoid this issue, a prior thermoset resin and hardener mixing was conducted carefully. The co-curing action between thermoset and thermoplastic resins was 
anticipated during this stage to further improve the adhesion. The outcome from the manufacturing stage was the hybrid composite with the glass fiber reinforcements to be subjected to cold spraying in the subsequent stage.
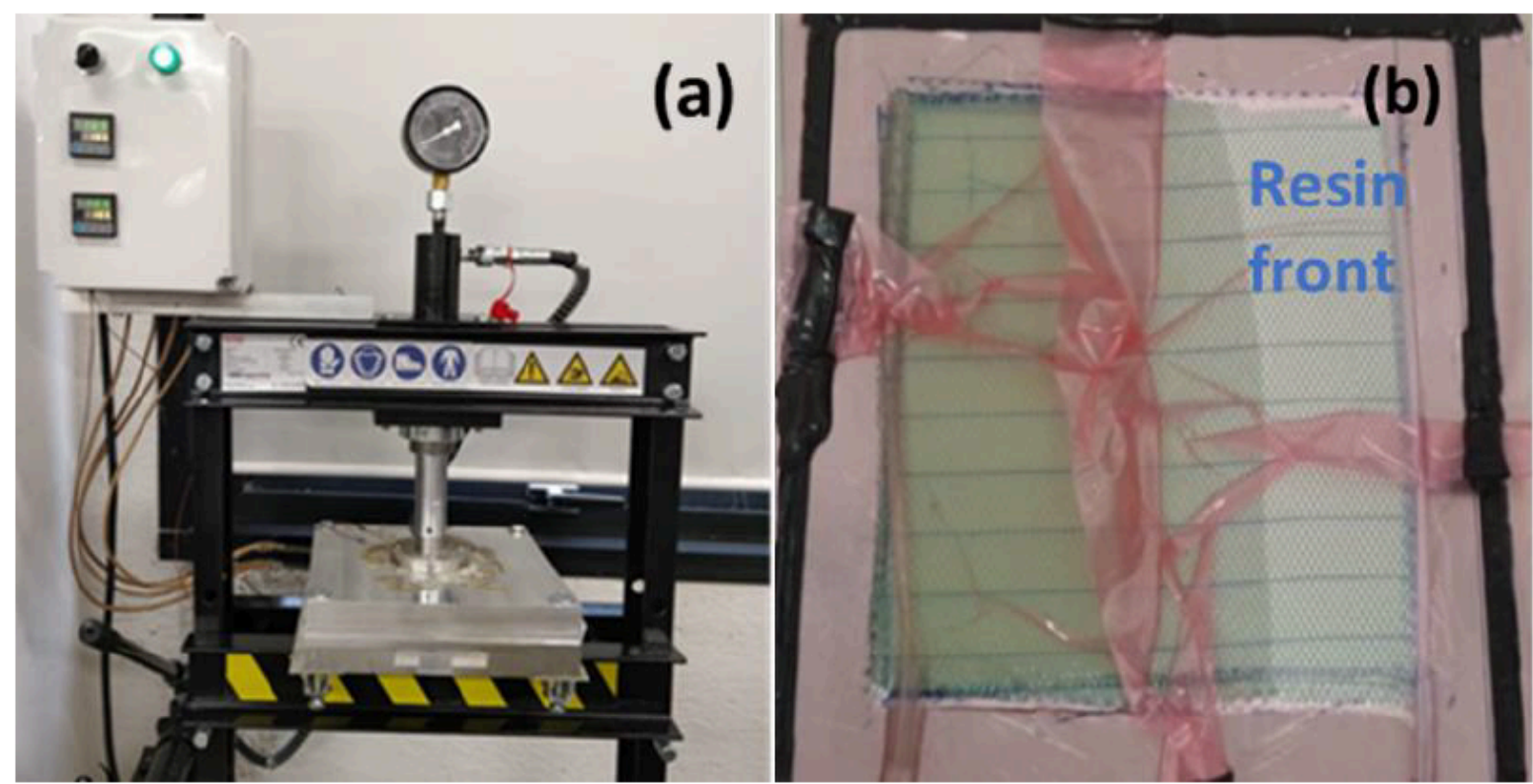

Fig. 1. (a) arrangement of the thermoplastic and reinforcement layer during the hot compaction, (b) resin infusion set up

- Metallization of the hybrid composite laminates

The metallization of hybrid composite laminate was obtained through the cold spraying technique, wherein the objective was to achieve the uniform and improved deposition on the imparted thermoplastic surface layer. The spraying process was conducted at SOPHIA TECH industrial unit. The effect of processing parameters on the coating deposition, quality and microstructure was analyzed. The DYCOMET 423 low pressure cold spray system (LPCS) was utilized for the cold spray phase. The system temperature can be attained in between $100{ }^{\circ} \mathrm{C}$ to about $600{ }^{\circ} \mathrm{C}$. For the cold spray process, two temperature levels were selected: T1 of about $110^{\circ} \mathrm{C}$, and T2 of about $200{ }^{\circ} \mathrm{C}$. Three stand-off distances were considered in the experiments, i.e. $20 \mathrm{~mm}, 25 \mathrm{~mm}$, and $30 \mathrm{~mm}$. The experiments were designed in combinations of the abovementioned temperature and stand-off distance values. The cold spraying pressure was kept at 5.5 bar during the deposition pass. The powder used for deposition was spherical aluminum-silicon alloy (AlSi10Mg) with an average diameter of $30 \mu \mathrm{m}$. The speed of advancement of the nozzle was set at $10 \mathrm{~mm} / \mathrm{sec}$.

\section{Results and discussion}

\subsection{Analysis of the manufactured hybrid composite panels}

The obtained glass fiber panels depicting the hybrid composite formation was subjected to the optical microscopic examinations. The results indicated a sound laminate preparation without significant porosity presence. The obtained laminates were subsequently analyzed after the metallization experiments. During the hot compaction stage of the composite manufacturing, the temperature increase ensured initially the softening and further transverse flow of PP in the fiber inter-tow regions occurred. It can be observed from the image (Fig. 2a). As a result, the prepared laminate was expected to have higher adhesion between the thermally softened PP layer and the adhered fiber reinforcement layer. 

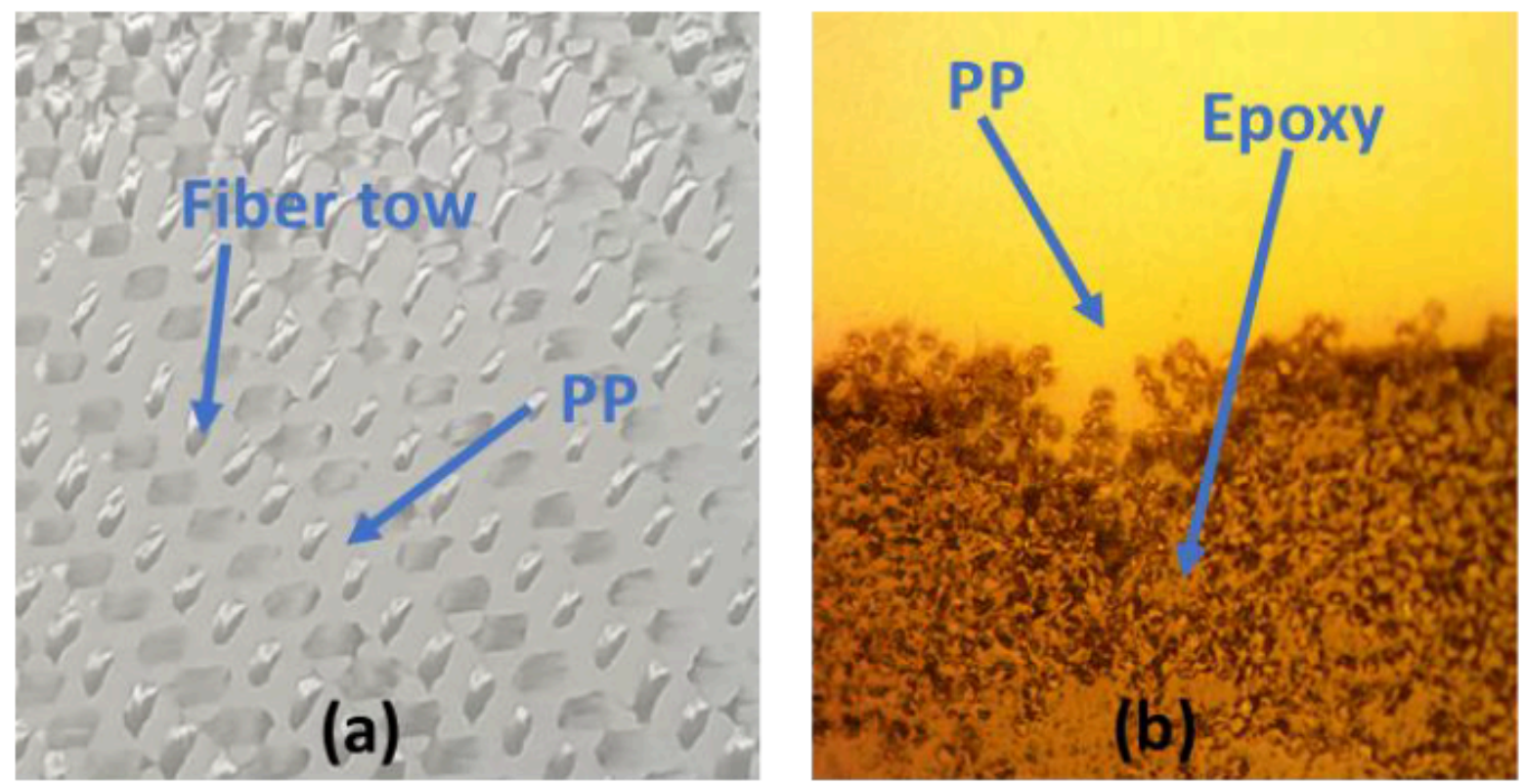

Fig. 2. (a) hot compacted laminate (b) micrograph illustrating the hybrid composite panel after the infusion process

Regarding the resin infusion stage, the optimal microscopic images illustrated the presence of both the softened PP and the cured epoxy throughout the different regions of the hybrid composite. The micrograph depicting the crosssectional view of the composite indicates three distinct regions comprising of first the PP layer adhered to the fiber reinforcement, second zone comprising of the Epoxy infused into the fiber reinforcement (Fig. 2b). The third zone is the boundary area distinguishing the first and second zone, which depicts a transition region with the flow of PP and cured epoxy inside the fiber reinforcement. It indicated the potential intermixing and curing of the resins throughout the fiber reinforcement layers.

\subsection{Analysis of the coating obtained by cold spray}

The cold spray processing parameters variation influenced the resultant coating formation. It can primarily be evidenced from the visual inspection and comparison of the glass fiber panels prepared before (Fig. 3 a) and after the spraying experiments (Fig. 3 b-m). 


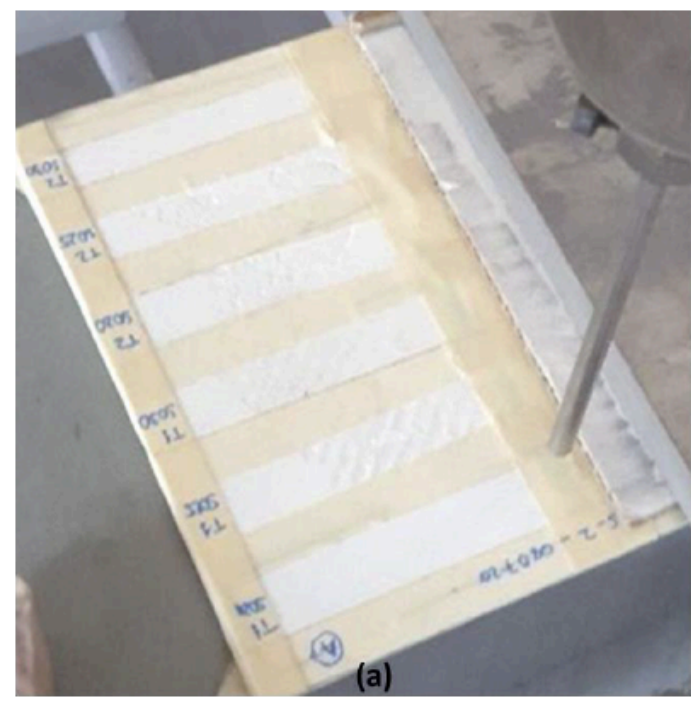

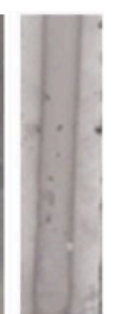

(b)

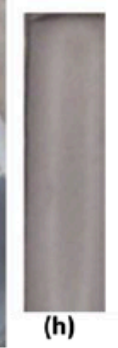

(h)

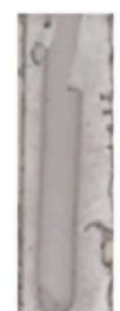

(c)

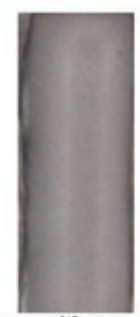

(i)

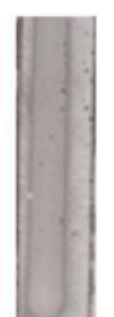

(d)

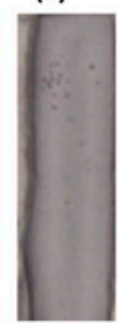

(j)

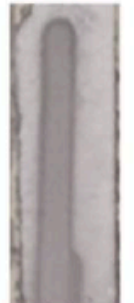

(e)

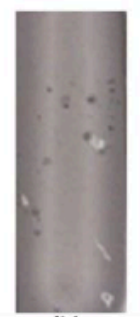

(k)

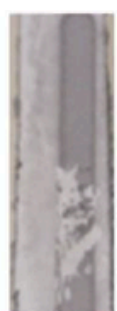

(f)

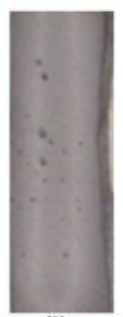

(I)

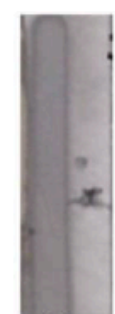

(g)

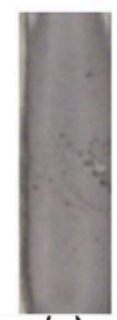

(m)

Fig. 3 (a) Composite panel placement for the metallic powder deposition in the cold spraying experimentation, Cold sprayed composite panels in the configuration of glass fiber placed above PP during the hot compaction with (b) T1, $20 \mathrm{~mm}$ (c) T1, $25 \mathrm{~mm}$ (d) T1, $30 \mathrm{~mm}$ (h) T2, $20 \mathrm{~mm}$ (i) T2, $25 \mathrm{~mm}$ (j) T2, $30 \mathrm{~mm}$, Cold sprayed composite panels in the configuration of glass fiber placed below PP during the hot compaction with (e) T1, 20 mm (f) T1, 25 mm (g) T1, $30 \mathrm{~mm}(\mathrm{k}) \mathrm{T} 2,20 \mathrm{~mm}$ (l) T2, $25 \mathrm{~mm}(\mathrm{~m}) \mathrm{T} 2,30 \mathrm{~mm}$

During the CS process, the general trend is the initial impingement of metallic particles at certain velocity level achieving the resultant particle-substrate and particle-particle interaction. The particle-substrate interaction, deformation, and deposition after the impingement is feasible in case of considering optimum processing conditions. The particle velocity should attain the critical velocity level at which the particle impact can generate the particle-substrate interaction. The particle penetration into the substrate surface is highly desirable under the circumstances of anticipating the particle anchorage with the host matrix. The mechanical interlocking mechanism does not occur in cases of employing the brittle nature substrate which can promote the severe substrate surface damage forming craters and opposing the particle penetration. In some cases of metallizing the thermoset based resin with fiber reinforcement, the damage in matrix removal as well as reinforcement damage is observed as well. The previously mentioned parameters combinations play integral role in deciding the ultimate coating achievement. The required amount of gas temperature raise can propel the effective deposition followed by the spraying pass movement. Also, the distance between the nozzle and the substrate surface i.e. stand-off distance can influence the particle impingement velocity and hence is one of the processing conditions governing the deposition. In this investigation, on the similar concept, different values of temperatures and standoff distances were selected by considering the materials properties of the substrate and depositing powders. The main focused processing parameters were the temperature and standoff distance. the hybrid composite prepared in two different configurations of glass fiber placement above and below the PP layer during the compaction were sprayed using the same process parameters.

As shown in Fig. 3 (b-g), condition of T1 temperature yielded almost no deposition in both the above and below configurations. Almost none or scarce deposition of AlSi10Mg was obtained in the initial experiments involving lower temperature values of $100{ }^{\circ} \mathrm{C}$ in correlation to each of the SoD values after one pass completion. Micrograph depicting the almost no deposition for the specific case of T1 temperature and highest $30 \mathrm{~mm}$ SoD can be visualized in Fig 4 a. The further changes in the design of experiments involved enhancing the temperature values up to T2 temperature $200{ }^{\circ} \mathrm{C}$, and different attempts involved predefined stand-off distance values (Fig. $3 \mathrm{~h}$-m). After single pass, for both 
the configurations of glass fiber placed above and below PP, the metallic layer was formed over the hybrid composite surface. In comparison, only changes in the fiber placement configuration does not appear to have significant influence. The cold spraying parameters variation yielded significant changes with regards to the coating formation. The uniform and continuous deposition throughout the length indicating the optimum set of parameters as the T2 temperature in combination with varying stand-off distances were obtained (Fig. 4 a, b). Such findings are attributed to the foremost effect of spraying processing parameter temperature and the hybrid composite being able to achieve the desirable matrix particle interaction upon the impingement.

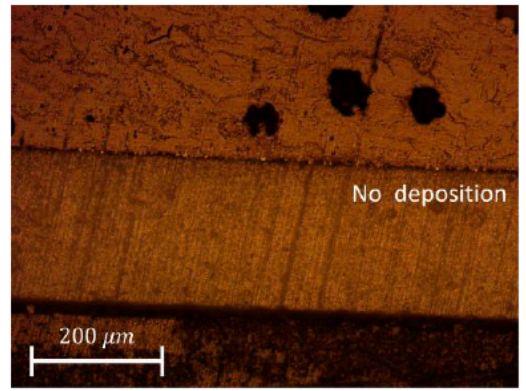

(a)

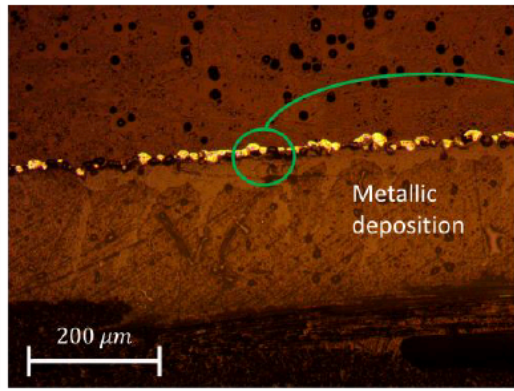

(b)

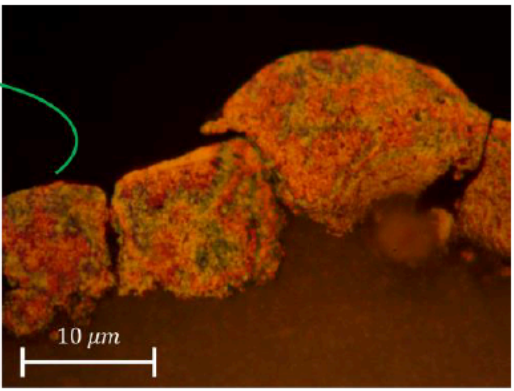

(c)

Fig. 4 Coating obtained with the different processing conditions (a) T1 temperature $100^{\circ} \mathrm{C}, 30 \mathrm{~mm}$ stand of distance, (b) T2 temperature $200^{\circ} \mathrm{C}, 30 \mathrm{~mm}$ stand of distance, (c) magnified view of the deposited coating

In detail, subsequent optical microscopic observation revealed a clear deformation and penetration into the substrate surface indicating towards a mechanical interlocking type of bonding mechanisms. This intriguing feature can be the potential reason behind the better mechanical anchorage of particle into the matrix. The enhancement in the temperature encourages this occurrence. Potentially the gas temperature raises the surface temperature of the particles transitioning towards the substrate surface. The higher kinetic velocity impact over the surface and upon impingement the heat dissipation from the heated metallic particles to the substrate surface results in the polymeric substrate surface softening. The softened polymeric matrix further provides a potential site to have a higher depth of penetration and envelops the deposition metallic particle generating a better anchorage between them. The prior literature studies support such elaboration; however, further investigations and characterizations will be conducted to confirm the claims. Moreover, another feature visible from the high magnification image in the Fig. 4 (c) demonstrates the particle-particle interaction upon the deformation. It is opportune in case of obtaining a continuous coating with higher adhesion.

\section{Conclusions}

Following conclusions can be drawn after the investigation comprising of the manufacturing and metallizing the fiber reinforced resin infused panels:

(1) a new approach, based on the manufacturing of a hybrid thermoplastic-thermoset laminate has been proposed, whereas enhanced adhesion is achieved by the combined impregnation of the reinforcement and co-curing of polymeric resins.

(2) preliminary tests highlighted that the processing window for the combined impregnation and co-curing is based on a proper calibration of temperature and pressure, whereas the gas temperature appeared as the most relevant parameters for the subsequent deposition of metallic powders. 


\section{Acknowledgements}

This research has received funding from the Italian Project, PRIN2017: Cold Spray of Metal-to-Composite (COSMEC), ministerial code 2017N4422T_001. The authors also acknowledge the industrial support from SOPHIA TECH industrial unit for facilitating the cold spraying experimentation.

\section{Bibliography}

[1] Rubino, F. Nisticò, A. Tucci, F. Carlone, P. Marine application of fiber reinforced composites: A review. J Mar Sci Eng 2020,8. doi:10.3390/JMSE8010026.

[2] Vedernikov, A. Safonov, A. Tucci, F. Carlone, P. Akhatov, I. Pultruded materials and structures: A review. J Compos Mater 2020. doi:10.1177/0021998320922894.

[3] Tucci, F. Bezerra, R. Rubino, F. Carlone, P. Multiphase flow simulation in injection pultrusion with variable properties. Mater Manuf Process 2020,35:152-62. doi:10.1080/10426914.2020.1711928.

[4] Vedernikov, A. Tucci, F. Carlone, P. Gusev, S. Konev, S. Firsov, D. Effects of pulling speed on structural performance of L-shaped pultruded profiles. Compos Struct 2021,255:112967. doi:10.1016/j.compstruct.2020.112967.

[5] Prisco, U. Impero, F. Rubino, F. Peck drilling of CFRP/titanium stacks: effect of tool wear on hole dimensional and geometrical accuracy. Prod Eng 2019,13:529-38. doi:10.1007/s11740-019-00915-1.

[6] Minchenkov, K. Vedernikov, A. Safonov, A. Akhatov, I. Thermoplastic pultrusion: A review. Polymers (Basel) 2021,13:1-36. doi:10.3390/polym13020180.

[7] Carlone, P. Rubino, F. Paradiso, V. Tucci, F. Multi-scale modeling and online monitoring of resin flow through dual-scale textiles in liquid composite molding processes. Int J Adv Manuf Technol 2018,96:2215-30. doi:10.1007/ s00170-018-1703-9.

[8] Askeland, DR. The Science and Engineering of Materials. Boston, MA: Springer US, 1996. doi:10.1007/ 978-1-4899-2895-5.

[9] Ganesan, A. Affi, J. Yamada, M. Fukumoto, M. Bonding behavior studies of cold sprayed copper coating on the PVC polymer substrate. Surf Coatings Technol 2012,207:262-9. doi:10.1016/j.surfcoat.2012.06.086.

[10] Małachowska, A. Winnicki, M. Stachowicz, M. Korzeniowski, M. Metallisation of polycarbonates using a low pressure cold spray method. Surf Eng 2018,34:251-8. doi:10.1080/02670844.2016.1277843.

[11] Giraud, D. Borit, F. Guipont, V. Jeandin, M. Malhaire, JM. Metallization of a polymer using cold spray: Application to aluminum coating of polyamide 66. Proc Int Therm Spray Conf 2012:265-70.

[12] Viscusi, A. Durante, M. Astarita, A. Boccarusso, L. Carrino, L. Perna, AS. Experimental evaluation of metallic coating on polymer by cold spray. Procedia Manuf 2020,47:761-5. doi:10.1016/j.promfg.2020.04.232.

[13] Frerichs, H. Stricker, J. Wesner, DA. Kreutz, EW. Laser-induced surface modification and metallization of polymers. Appl Surf Sci 1995,86:405-10. doi:10.1016/0169-4332(94)00431-5.

[14] Siegel, J. Kotal, V. Preparation of Thin Metal Layers on Polymers. Acta Polytech 2007,47. doi:10.14311/904.

[15] Southward, RE. Thompson, DW. Reflective and conductive silvered polyimide films for space applications prepared 
via a novel single-stage self-metallization technique. Mater Des 2001,22:565-76. doi:10.1016/S0261-3069(01)00017-6.

[16] Shacham-Diamand, Y. Osaka, T. Okinaka, Y. Sugiyama, A. Dubin, V. 30 Years of electroless plating for semiconductor and polymer micro-systems. Microelectron Eng 2015,132:35-45. doi:10.1016/j.mee.2014.09.003.

[17] Gonzalez, R. Ashrafizadeh, H. Lopera, A. Mertiny, P. McDonald, A. A Review of Thermal Spray Metallization of Polymer-Based Structures. J Therm Spray Technol 2016,25:897-919. doi:10.1007/s11666-016-0415-7.

[18] Chen, C. Xie, X. Xie, Y. Yan, X. Huang, C. Deng, S. Metallization of polyether ether ketone (PEEK) by copper coating via cold spray. Surf Coatings Technol 2018,342:209-19. doi:10.1016/j.surfcoat.2018.02.087.

[19] Grujicic, M. Zhao, CL. DeRosset, WS. Helfritch, D. Adiabatic shear instability based mechanism for particles/substrate bonding in the cold-gas dynamic-spray process. Mater Des 2004,25:681-8. doi:10.1016/j.matdes.2004.03.008.

[20] Villafuerte, J. Current and future applications of cold spray technology. Met Finish 2010,108:37-9. doi:10.1016/ S0026-0576(10)80005-4.

[21] Yin, S. Wang, X. Li, W. Liao, H. Jie, H. Deformation behavior of the oxide film on the surface of cold sprayed powder particle. Appl Surf Sci 2012,259:294-300. doi:10.1016/j.apsusc.2012.07.036.

[22] Che, H. Vo, P. Yue, S. Investigation of Cold Spray on Polymers by Single Particle Impact Experiments. J Therm Spray Technol 2019,28:135-43. doi:10.1007/s11666-018-0801-4.

[23] Viscusi, A. Astarita, A. Gatta, R Della. Rubino, F. A perspective review on the bonding mechanisms in cold gas dynamic spray. Surf Eng 2019,35:743-71. doi:10.1080/02670844.2018.1551768.

[24] King, PC. Poole, AJ. Horne, S. de Nys, R. Gulizia, S. Jahedi, MZ. Embedment of copper particles into polymers by cold spray. Surf Coatings Technol 2013,216:60-7. doi:10.1016/j.surfcoat.2012.11.023.

[25] Stenson, C. McDonnell, KA. Yin, S. Aldwell, B. Meyer, M. Dowling, DP. Cold spray deposition to prevent fouling of polymer surfaces. Surf Eng 2018,34:193-204. doi:10.1080/02670844.2016.1229833.

[26] Lupoi, R. Stenson, C. McDonnell, KA. Dowling, DP. Ahearne, E. Antifouling coatings made with Cold Spray onto polymers: Process characterization. CIRP Ann - Manuf Technol 2016,65:545-8. doi:10.1016/j.cirp.2016.04.015.

[27] Małachowska, A. Winnicki, M. Konat, Ł. Piwowarczyk, T. Pawłowski, L. Ambroziak, A. Possibility of spraying of copper coatings on polyamide 6 with low pressure cold spray method. Surf Coatings Technol 2017,318:82-9. doi:10.1016/j.surfcoat.2017.02.001.

[28] Kromer, R. Danlos, Y. Aubignat, E. Verdy, C. Costil, S. Coating deposition and adhesion enhancements by laser surface texturing-metallic particles on different classes of substrates in cold spraying process. Mater Manuf Process 2017,32:1642-52. doi:10.1080/10426914.2017.1364750.

[29] Rokni, MR. Feng, P. Widener, CA. Nutt, SR. Depositing Al-Based Metallic Coatings onto Polymer Substrates by Cold Spray. J Therm Spray Technol 2019,28:1699-708. doi:10.1007/s11666-019-00911-y.

[30] Zhang, D. Shipway, PH. McCartney, DG. Cold Gas Dynamic Spraying of Aluminum: The Role of Substrate Characteristics in Deposit Formation. J Therm Spray Technol 2005,14:109-16. doi:10.1361/10599630522666.

[31] Che, H. Chu, X. Vo, P. Yue, S. Metallization of Various Polymers by Cold Spray. J Therm Spray Technol 2018,27:169-78. doi:10.1007/s11666-017-0663-1. 
[32] Che, H. Yue, S. Vo, P. Nobari, A. Da Silva Marques, A. Metallization of polymers by cold spraying with low melting point powders. Proc. Int. Therm. Spray Conf., vol. 2019- May, 2019, p. 586-91.

[33] Gardon, M. Latorre, A. Torrell, M. Dosta, S. Fernández, J. Guilemany, JM. Cold gas spray titanium coatings onto a biocompatible polymer. Mater Lett 2013,106:97-9. doi:10.1016/j.matlet.2013.04.115.

[34] Gillet, V. Aubignat, E. Costil, S. Courant, B. Langlade, C. Casari, P. Development of low pressure cold sprayed copper coatings on carbon fiber reinforced polymer (CFRP). Surf Coatings Technol 2019,364:306-16. doi:10.1016/ j.surfcoat.2019.01.011.

[35] Bortolussi, V. Borit, F. Chesnaud, A. Jeandin, M. Faessel, M. Figliuzzi, B. Cold spray of metal-polymer composite coatings onto Carbon Fiber-Reinforced Polymer (CFRP). Proc Int Therm Spray Conf 2016,1:437-43.

[36] Bortolussi, V. Figliuzzi, B. Willot, F. Faessel, M. Jeandin, M. Electrical Conductivity of Metal-Polymer Cold Spray Composite Coatings onto Carbon Fiber-Reinforced Polymer. J Therm Spray Technol 2020,29:642-56. doi:10.1007/ s11666-020-00999-7.

[37] Zhou, XL. Chen, AF. Liu, JC. Wu, XK. Zhang, JS. Preparation of metallic coatings on polymer matrix composites by cold spray. Surf Coatings Technol 2011,206:132-6. doi:10.1016/j.surfcoat.2011.07.005.

[38] Sturgeon, A. Dunn, B. Celotto, S. O’Neill, B. Cold sprayed coatings for polymer composite substrates. Eur Sp Agency, (Special Publ ESA SP 2006.

[39] Liberati, A. Che, H. Yue, S. Vo, P. Cold spraying of mixed SN-AI powders onto carbon fibre reinforced polymers. Proc Int Therm Spray Conf 2018,2018-May:166-72.

[40] Affi, J. Okazaki, H. Yamada, M. Fukumoto, M. Fabrication of aluminum coating onto CFRP substrate by cold spray. Mater Trans 2011,52:1759-63. doi:10.2320/matertrans.T-M2011807.

[41] Che, H. Chu, X. Vo, P. Yue, S. Cold spray of mixed metal powders on carbon fibre reinforced polymers. Surf Coatings Technol 2017,329:232-43. doi:10.1016/j.surfcoat.2017.09.052.

[42] Che, H. Vo, P. Yue, S. Metallization of carbon fibre reinforced polymers by cold spray. Surf Coatings Technol 2017,313:236-47. doi:10.1016/j.surfcoat.2017.01.083.

[43] Ganesan, A. Yamada, M. Fukumoto, M. Cold spray coating deposition mechanism on the thermoplastic and thermosetting polymer substrates. J Therm Spray Technol 2013,22:1275-82. doi:10.1007/s11666-013-9984-x.

[44] Rubino, F. Tucci, F. Esperto, V. Perna, AS. Astarita, A. Carlone, P. Metallization of Fiber Reinforced Composite by Surface Functionalization and Cold Spray Deposition. 23rd Int. Conf. Mater. Form. (ESAFORM 2020), 2019.

PDF automatically generated on 2021-05-20 05:31:09

Article url: https://popups.uliege.be/esaform21/index.php?id=2727

published by ULiège Library in Open Access under the terms and conditions of the CC-BY License (https://creativecommons.org/licenses/by/4.0) 